\title{
GAMBARAN PROFESSIONAL QUALITY OF LIFE (PROQOL) GURU ANAK BERKEBUTUHAN KHUSUS
}

\author{
Dewa Ayu Inten Purnamasari ${ }^{1}$, Heryanti Satyadi $^{2}$, Rostiana $^{3}$ \\ ${ }^{1}$ Program Studi Magister Psikologi Profesi, Universitas Tarumanagara, Jakarta \\ Email: dewa.717172005@stu.untar.ac.id \\ ${ }^{2}$ Fakultas Psikologi, Universitas Tarumanagara, Jakarta \\ Email: heryanti.satyadi@gmail.com \\ ${ }^{3}$ Fakultas Psikologi, Universitas Tarumanagara, Jakarta \\ Email:rostiana@fpsi.untar.ac.id
}

Masuk : 21-04-2020, revisi: 31-10-2020, diterima untuk diterbitkan : 31-10-2020

\begin{abstract}
Professional Quality of Life (ProQOL) is a topic that has been growing for the last 20 years. Stamm is an expert who is developing theoretical concepts and its instrument in 2010. ProQOL explains individual's perceptions professional quality of life, which consists of two aspects. Compassion Satisfaction (CS) is the positive aspect where someone is able to feel positive feelings such as altruism while working and Compassion Fatigue (CF) is the negative ones, where someone feels uncomfortable which can leads to Burnout and Secondary Traumatic Stress (STS) symptoms. Most of study has investigated ProQOL among health caring professional, therefore this study aims to overview ProQOL among special education teachers. Uses quantitative-non experimental design, this study involves 171 special education teachers as participants. Based on the collected data, it shows that individual's perceptions about the quality of life as a special education teacher tends to be positive. However, this is not necessarily followed by low STS and burnout rates. This study found that around 77\% teachers were at moderate to high burnout levels, while $72 \%$ also had moderate to high STS levels.
\end{abstract}

Keywords: PROQOL, CS, CF, burnout, STS

\begin{abstract}
ABSTRAK
Professional Quality of Life (ProQOL) merupakan sebuah topik yang sudah berkembang sejak 20 tahun terakhir. Seorang ahli bernama Stamm telah berjasa dalam mengembangkan konsep teoretis ProQOL beserta alat ukurnya pada tahun 2010. ProQOL menjelaskan persepsi individu mengenai kualitas hidup profesionalnya, yang terdiri dari dua aspek. Compassion Satisfaction (CS) merupakan aspek positif dimana individu mampu merasakan perasaan positif, altruisme terkait perkerjaannya dan Compassion Fatigue (CF) yang merupakan aspek negatif, dimana individu merasa tidak nyaman dalam menjalankan pekerjaannya yang berujung pada gejala Burnout dan Secondary Traumatic Stress (STS). Oleh karena sebagian besar penelitian mengenai ProQOL telah diteliti pada tenaga profesional kesehatan, penelitian ini bertujuan untuk memperoleh gambaran ProQOL pada profesi guru ABK. Penelitian ini merupakan penelitian kuantitatif non-eksperimental yang melibatkan 171 guru ABK sebagai partisipan. Berdasarkan data yang terkumpul diperoleh bahwa persepsi individu terhadap kualitas hidup profesional sebagai guru ABK cenderung positif. Akan tetapi, hal tersebut tidak serta merta diikuti dengan tingkat burnout dan STS yang rendah. Berdasarkan hasil penelitian, sekitar 77\% guru ABK berada pada tingkat burnout Sedang-Tinggi dan $72 \%$ diantaranya juga memiliki tingkat STS Sedang-Tinggi.
\end{abstract}

Kata Kunci: PROQOL, CS, CF, burnout, STS

\section{PENDAHULUAN}

Kualitas hidup profesional atau Professional Quality of Life (ProQOL) merupakan sebuah topik yang sudah berkembang dalam kurun 20 tahun terakhir. Stamm (2010) dalam publikasinya mendefinisikan ProQOL sebagai kualitas yang dapat dirasakan individu terkait hubungannya dengan bidang pekerjaan mereka sebagai penolong. Beberapa bidang pekerjaan yang dimaksud antara lain adalah para tenaga profesional kesehatan, pekerja sosial, guru, petugas kepolisian, petugas pemadam kebakaran, petugas transportasi, maupun petugas penanggulangan bencana. ProQOL dipengaruhi oleh dua aspek, yakni aspek positif dan aspek negatif. Aspek positif disebut dengan Compassion Satisfaction (CS), dimana individu merasakan perasaan positif, altruisme, 
karena mampu membantu atau menolong orang lain. Sedangkan aspek lainnya yang berlawanan disebut dengan Compassion Fatigue (CF) dimana individu merasakan perasaan tidak nyaman yang dapat menyebabkan gejala kelelahan emosional, frustrasi, kemarahan, depresi, hingga PostTraumatic Stress Disorder (PTSD). Dalam hal ini, CF memiliki dua elemen penyusun, yakni burnout dan Secondary Traumatic Stress (STS).

Burnout merupakan elemen pertama penyusun CF yang diasosiasikan dengan perasaan putus asa dan timbulnya kesulitan untuk melakukan pekerjaan secara efektif (Stamm, 2010). Maslach \& Leiter (2016) menjelaskan burnout sebagai sindrom psikologis yang muncul sebagai respon dari stres yang berkepanjangan di tempat kerja. Gejala burnout biasanya muncul secara bertahap dan diiringi dengan gejala lain yang menyertai seperti kelelahan, frustrasi, dan rasa marah yang tidak terkendali (Stamm, 2010). Elemen penyusun CF yang kedua adalah STS yang merupakan perasaan negatif yang muncul akibat tekanan, rasa takut, maupun cemas saat memberikan pertolongan atau perawatan pada orang lain (Kelly, Runge, \& Spencer, 2015). Trauma terkait pekerjaan lebih mungkin dialami oleh mereka yang pernah melewati serangkaian peristiwa penuh tekanan, terutama dalam bidang pekerjaan yang berhubungan dengan perawatan individu, seperti dokter dan perawat (Beck, 2011). STS juga dapat menimbulkan gejala seperti sulit tidur, perasaan yang mengganggu, hingga berusaha menghindari pekerjaan karena teringat peristiwa buruk yang pernah dialami sebelumnya (Stamm, 2010).

Seiring dengan perkembangannya, penelitian mengenai ProQOL sebagian besar telah dilakukan pada sampel tenaga profesional kesehatan. Berdasarkan sintesa beberapa penelitian, profesi dokter dan perawat dianggap sangat penting dalam melakukan pertolongan, seperti upaya penyelamatan hidup pasien maupun serangkaian proses perawatan dan pemulihan bagi pasien yang sedang sakit. Hal tersebut menyebabkan mereka memiliki risiko tinggi mengalami gejala kelelahan emosional yang berujung pada burnout maupun gejala STS akibat tuntutan tugas yang tinggi serta beban kerja yang berat (Kelly, Runge, \& Spencer, 2015; Craigie et al., 2016; Yu, Jiang, \& Shen, 2016; Austin, Saylor, \& Finley, 2017; Andriani, Rustiyaningsih, \& Haryanti, 2017). Akan tetapi, meskipun CS juga merupakan salah satu aspek dari ProQOL, penelitian yang membahas mengenai CS masih terbilang minim. Hal tersebut dikarenakan sebagian besar penelitian lebih berfokus pada CF serta dampaknya bagi individu, padahal CF dan CS merupakan persepsi yang dihasilkan dari masing-masing individu mengenai kualitas hidup profesionalnya (Kelly, Runge, \& Spencer, 2015).

Merujuk pada uraian di atas, tuntutan tugas yang tinggi serta beratnya beban kerja sebagai penolong sebenarnya tidak hanya terbatas pada tenaga profesional kesehatan. Seperti yang telah disinggung sebelumnya, Stamm (2010) juga menyebutkan beberapa profesi lain yang terkait, salah satunya adalah guru. Guru merupakan sebuah profesi yang identik dengan mengajar. Johnson (dalam Koenig, Rodger, \& Specht, 2017) mengemukakan bahwa mengajar juga merupakan sebuah profesi dengan tingkat stres yang hampir sama dengan tenaga profesional kesehatan, petugas kepolisian, dan pekerja sosial. Dalam Undang-Undang Republik Indonesia Nomor 14 Tahun 2005, guru adalah pendidik profesional dengan tugas utama mendidik, mengajar, membimbing, mengarahkan, melatih, menilai, dan mengevaluasi peserta didik pada pendidikan anak usia dini jalur pendidikan formal, pendidikan dasar, dan pendidikan menengah. Bersesuaian dengan tugas tersebut, Harden \& Crosby (2000) juga menguraikan enam tugas pokok dan peran guru yakni sebagai sebagai pemberi informasi, role model, fasilitator, asesor, perencana, sekaligus sebagai pengembang sumber daya. 
Peran dan tugas pokok guru yang diuraikan di atas, tentu saja tidak hanya diperuntukkan bagi guru yang mengajar di jenjang pendidikan formal, sebab Undang-Undang Republik Indonesia Nomor 20 Tahun 2003 juga menguraikan bahwa selain jenjang pendidikan formal, juga terdapat pendidikan khusus yang diperuntukkan bagi peserta didik yang memiliki tingkat kesulitan dalam mengikuti proses pembelajaran karena kelainan fisik, emosional, mental, sosial, dan/atau memiliki potensi kecerdasan dan bakat istimewa. Peserta didik dengan kategori tersebut dapat mengenyam pendidikan di sebuah lembaga pendidikan formal yang disebut dengan Sekolah Luar Biasa atau SLB (Pramartha, 2015). Mereka juga dapat menempuh pendidikan di sekolah inklusif, yaitu sekolah reguler yang juga menerima peserta didik dengan kebutuhan khusus (Komariyah, Bagarkorowati, \& Lianty, 2017).

Profesi guru bagi Anak Berkebutuhan Khusus (ABK) merupakan sebuah profesi yang memiliki tantangan. Hapsari (2016) berpendapat bahwa tugas dan tanggung jawab mereka lebih kompleks karena mereka dihadapkan pada situasi mengajar, mengasuh serta membimbing para peserta didik dengan penanganan yang khusus. Hal ini juga sejalan dengan pendapat Wahyuni \& Rosdiana (dalam Firmansyah \& Widuri, 2014) dimana guru yang mengajar di Sekolah Luar Biasa (SLB) harus memiliki ketekunan dan kesabaran yang lebih ekstra dibandingkan dengan profesi guru lainnya, karena dibutuhkan pula unsur keikhlasan dalam pengabdian agar mampu memahami kebutuhan peserta didik.

Penelitian yang membahas mengenai ProQOL dengan sampel guru ABK juga masih lebih banyak berfokus pada aspek CF dibandingkan CS-nya. Berdasarkan sintesa beberapa penelitian yang dimuat dalam Sharp-Donahoo, Siegrist, \& Garrett-Wright (2017) ditemukan beberapa faktor yang dihubungkan dengan tingginya tingkat stres dan burnout pada guru ABK, diantaranya adalah kurangnya atensi siswa, kelemahan siswa secara akademis, serta perilaku siswa yang abusive. Temuan lain dalam penelitian tersebut juga menjelaskan bahwa guru ABK yang terlalu empati dan penyayang juga rentan mengalami STS. Hal tersebut dikarenakan empati merupakan salah satu faktor utama yang dapat menimbulkan stres berkepanjangan pada individu.

Sementara itu di sisi lain, masih sulit menemukan studi yang membahas mengenai aspek CS pada profesi guru ABK, padahal kualitas kehidupan profesional tidak harus selalu dilihat dari aspek negatifnya saja melainkan juga aspek positif yang mempengaruhinya. Berdasarkan latar belakang tersebut, penelitian ini bertujuan untuk mengetahui gambaran ProQOL pada profesi guru ABK, dimana gambaran ini akan menguraikan kedua aspek ProQOL, yakni CS dan CF.

\section{METODE PENELITIAN}

\section{Partisipan dan Prosedur Penelitian}

Penelitian ini menggunakan desain kuantitatif-non eksperimental. Partisipan dalam penelitian ini adalah guru/pengajar ABK, baik yang mengajar di Sekolah Khusus (SKH) maupun Sekolah Luar Biasa (SLB) yang tersebar di daerah Jakarta dan Tangerang. Teknik sampling yang digunakan dalam penelitian ini adalah teknik non probability sampling yakni convenience sampling. Partisipan terkumpul sebanyak 171 orang dengan rentang usia 20 hingga 60 tahun. Partisipan diminta untuk mengisi kuesioner ProQOL yang terdiri dari 30 butir pernyataan, lebih lanjut akan diuraikan dalam subbab instrumen penelitian.

\section{Instrumen Penelitian}

Penelitian ini menggunakan alat ukur ProQOL yang dikembangkan oleh Stamm (2010). ProQOL terdiri dari 3 subskala, yakni CS, Burnout, dan STS. Masing-masing subskala terdiri atas 10 butir pernyataan, sehingga secara keseluruhan ProQOL memuat 30 butir pernyataan. 
Adaptasi ProQOL ke dalam Bahasa Indonesia pertama kali dilakukan oleh Eka, dkk (2016) dalam penelitian yang melibatkan sampel perawat. Selang beberapa waktu kemudian, Sutjiono (2018) melakukan evaluasi psikometris ProQOL dengan sampel guru ABK. Dari hasil evaluasi psikometris tersebut, diperoleh internal konsistensi Alpha Cronbach subskala CS sebesar 0,851; subskala Burnout sebesar 0,742; dan subskala STS sebesar 0,798. Selain itu, ditunjukkan pula bahwa terdapat bukti validitas alat ukur, yakni validitas isi melalui serangkaian proses penilaian yang telah dilakukan oleh para ahli (expert judgement), validitas kriteria dengan menggunakan alat ukur pembanding yang sejenis yakni SWLS dan DASS, serta validitas konstruk yang dianalisis menggunakan CFA. Dari hasil tersebut diperoleh bahwa alat ukur ProQOL telah dinyatakan valid dan reliabel untuk digunakan sebagai instrumen pengambilan data pada guru ABK. Adapun contoh butir pernyataan pada masing-masing subskala antara lain: subskala CS "Saya menyukai pekerjaan saya sebagai guru ABK"; subskala Burnout "Saya merasa kelelahan karena pekerjaan saya sebagai guru ABK."; dan subskala STS "Saya merasa tertekan karena pengalaman traumatis dari siswa yang saya ajarkan." Masing-masing pernyataan menyediakan lima alternatif pilihan jawaban dari rentang 1 sampai dengan 5 dengan rincian: $1=$ Tidak Pernah, 2 = Jarang, 3 = Kadang-Kadang, $4=$ Sering, $5=$ Selalu .

\section{HASIL DAN PEMBAHASAN}

Berdasarkan data yang terkumpul dari 171 partisipan, 34 partisipan $(20 \%)$ berjenis kelamin lakilaki, sementara 137 partisipan lainnya (80\%) berjenis kelamin perempuan. Selanjutnya, data dari kelompok usia menunjukkan bahwa 59\% partisipan berada di rentang usia 20 hingga 34 tahun, sementara $41 \%$ lainnya berada di rentang usia 35 hingga 59 tahun. Berdasarkan jenjang pendidikan terakhir, diperoleh bahwa sebagian besar partisipan (80\%) memiliki latar belakang pendidikan terakhir S1, sementara $20 \%$ lainnya memiliki latar belakang pendidikan terakhir jenjang SMA/SMK, D1, D2, D3, dan S2.

Bila ditinjau dari rata-rata skor yang diperoleh, kualitas hidup profesional guru ABK memiliki rata-rata skor CS yang lebih tinggi dibandingkan skor burnout dan STS. Skor CS yang lebih tinggi menunjukkan bahwa persepsi individu terhadap kualitas hidup profesional sebagai guru ABK cenderung positif. Selain dapat merasakan perasaan yang positif, skor CS yang tinggi juga merepresentasikan bahwa individu merasa puas dengan bidang pekerjaan mereka. Mereka merasa senang karena mampu memberikan pertolongan kepada orang lain. Selain itu, kepuasan juga dapat berasal dari organisasi/institusi tempat mereka bekerja (Stamm, 2010).

Tabel 1. Gambaran PROQOL pada Guru ABK

\begin{tabular}{cccc} 
Indikator & $\mathbf{N}$ & $\mathbf{M}$ & SD \\
\hline CS & 171 & 3.98 & 0.48 \\
\hline Burnout & 171 & 2.01 & 0.43 \\
\hline STS & 171 & 2.00 & 0.52 \\
\hline
\end{tabular}

Selanjutnya, bila ditinjau berdasarkan tabel kategorisasi, diperoleh hasil bahwa pada kedua aspek, baik CS maupun CF (burnout dan STS) sebagian besar berada pada kategori Sedang. Bila dikaitkan dengan temuan sebelumnya, meskipun skor rata-rata CS cenderung tinggi, akan tetapi tidak serta merta diikuti dengan tingkat burnout dan STS yang rendah. Terbukti dari hasil yang diperoleh dalam penelitian ini, bahwa sekitar $77 \%$ guru ABK berada pada tingkat burnout Sedang-Tinggi dan $72 \%$ diantaranya juga memiliki tingkat STS Sedang-Tinggi. Data tersebut memberikan informasi bahwa kualitas hidup profesional memang sangat bergantung pada persepsi masing-masing individu, bagaimana mereka mengidentifikasi CS dan CF-nya (Kelly, Runge, \& Spencer, 2015) dan bahwa kedua aspek tersebut memang saling berkaitan satu sama 
lain tergantung bagaimana individu merasakan dan mempersepsikan pengalamannya dalam bekerja.

Tabel 2. Kategorisasi CS pada guru ABK

\begin{tabular}{ccc} 
Kategori $\boldsymbol{C S}$ & Frekuensi (orang) & Persentase (\%) \\
\hline Rendah & 54 & 31.6 \\
\hline Sedang & 69 & 40.4 \\
\hline Tinggi & 48 & 28.1 \\
\hline Total & 171 & 100 \\
\hline
\end{tabular}

Tabel 3. Kategorisasi Burnout pada guru ABK

\begin{tabular}{ccc} 
Kategori Burnout & Frekuensi (orang) & Persentase (\%) \\
\hline Rendah & 50 & 29.2 \\
\hline Sedang & 82 & 48.0 \\
\hline Tinggi & 39 & 22.8 \\
\hline Total & 171 & 100 \\
\hline
\end{tabular}

Tabel 4. Kategorisasi STS pada guru ABK

\begin{tabular}{ccc} 
Kategori STS & Frekuensi (orang) & Persentase (\%) \\
\hline Rendah & 30 & 17.5 \\
\hline Sedang & 94 & 55.0 \\
\hline Tinggi & 47 & 27.5 \\
\hline Total & 171 & 100 \\
\hline
\end{tabular}

Adanya dua aspek dalam kualitas hidup profesional, tidak pernah terlepas dari faktor-faktor yang juga menyertai. Stamm (2010) mengemukakan bahwa setidaknya terdapat 3 faktor utama yang memainkan peranan, yakni work environment (lingkungan pekerjaan), client environment (kondisi klien/penerima jasa), dan person environment (lingkungan/keadaan individu itu sendiri). Ketiga faktor ini akan berinteraksi secara berkesinambungan, dalam menentukan aspek mana yang akan lebih dominan dirasakan oleh individu, CS atau CF-nya.

Pada penelitian ini, berdasarkan uji Kruskal-Wallis, ditemukan bahwa terdapat perbedaan STS yang signifikan ditinjau dari durasi mengajar guru per-hari, dengan nilai $\mathrm{H}=9.297, \mathrm{p}=0.02<$ 0.05. Durasi mengajar dalam hal ini merupakan kondisi lingkungan kerja yang juga berkaitan dengan intensitas interaksi yang terjalin antara guru (individu) dan siswa (klien). Para ahli (dalam Koenig, 2014) berpendapat bahwa interaksi empatik yang terjalin erat memang berpotensi menimbulkan gejala CF pada individu. Hal ini juga diperkuat oleh hasil penelitian Duarte, Pinto-Gouveia, \& Cruz (2016), dimana perasaan empati merupakan faktor risiko CF yang tinggi.

Tabel 5. Uji Kruskal-Wallis STS dan Durasi Mengajar

\begin{tabular}{cccccc}
\hline & N & STS & & \\
\hline Durasi Mengajar/Hari & 8 & Mean Rank & Chi-Square & Sig. \\
\hline $2-3$ jam & 43 & 66.25 & & \\
\hline $4-5$ jam & 68 & 72.71 & & \multirow{2}{*}{9.297} & \multirow{2}{*}{026} \\
\hline $6-7$ jam & 52 & 98.99 & & \\
\hline $8-9$ jam & 171 & 83.04 & & \\
\hline Total & \multicolumn{2}{c}{} & &
\end{tabular}

Selain itu, ditemukan pula bahwa terdapat perbedaan CS yang signifikan ditinjau dari tingkat kepuasan penghasilan dengan nilai $\mathrm{H}=8.688, \mathrm{p}=0.034<0.05$. Hal ini sejalan dengan pendapat 
Dvorak \& Philips (dalam Msuya, 2016) bahwa gaji/penghasilan merupakan salah satu faktor ekstrinsik yang cukup berperan dalam tingkat kepuasan kerja guru.

Tabel 6. Uji Kruskal-Wallis CS dan Tingkat Kepuasan Penghasilan

\begin{tabular}{cccccc}
\hline & \multicolumn{3}{c}{ STS } & & \\
\hline $\begin{array}{c}\text { Tingkat Kepuasan } \\
\text { Penghasilan }\end{array}$ & N & Mean Rank & Chi-Square & Sig. \\
\hline Sangat Tidak Puas & 3 & 91.50 & & \\
\hline Tidak Puas & 72 & 73.00 & & \multirow{2}{*}{8.688} & .034 \\
\hline Puas & 95 & 95.48 & & \\
\hline Sangat Puas & 1 & 104.50 & & \\
\hline Total & 171 & \multicolumn{2}{l}{} & &
\end{tabular}

\section{KESIMPULAN DAN SARAN}

Berdasarkan hasil penelitian yang telah diuraikan di atas, dapat disimpulkan bahwa guru ABK merasa puas dengan bidang pekerjaan mereka. Mereka menilai bahwa profesi sebagai guru ABK mampu memberikan aspek yang positif (CS) dan bermanfaat bagi orang lain. Akan tetapi meski demikian, kemungkinan/risiko terjadinya burnout maupun STS juga tidak dapat dihindari. Hasil penelitian menunjukkan bahwa sekitar $77 \%$ guru ABK berada pada tingkat burnout SedangTinggi dan $72 \%$ diantaranya juga memiliki tingkat STS Sedang-Tinggi. Kualitas hidup profesional sejatinya merupakan persepsi masing-masing individu yang dipengaruhi oleh banyak faktor, dimana faktor tersebut saling terkait satu sama lain. Meskipun CS dan CF merupakan aspek yang saling berkebalikan, namun seperti dua sisi koin, mereka akan selalu berdampingan tergantung bagaimana individu mempersepsikan pengalaman untuk menentukan kualitas hidupnya sebagai seorang tenaga profesional.

Penelitian selanjutnya diharapkan dapat mengkaji ProQOL pada bidang pekerjaan/profesi lain agar hasil penelitian yang didapatkan juga lebih berkembang dan bervariasi. Penelitian mengenai ProQOL ke depannya juga diharapkan dapat mengaitkan beberapa faktor internal, terutama aspek psikologis individu seperti kecenderungan kepribadian atau kecerdasan emosi untuk memperoleh dinamika yang lebih komprehensif mengenai kaitannya dengan aspek CS dan CF. Selain itu, kajian studi yang lebih mendalam juga dapat dirancang untuk mengetahui interaksi dari faktor-faktor terkait, sehingga ke depannya referensi mengenai CS dan CF tidak hanya sebatas membahas mengenai konstruk teoretis saja namun juga dapat digunakan sebagai acuan untuk merumuskan strategi/saran bagi individu maupun institusi terkait agar aspek positif dari kualitas hidup para tenaga profesional dapat terus ditingkatkan.

\section{Ucapan Terima Kasih (Acknowledgement)}

Peneliti mengucapkan terima kasih kepada seluruh guru yang telah bersedia terlibat sebagai partisipan di dalam penelitian ini. Selain itu, peneliti juga mengucapkan terima kasih kepada sekolah-sekolah dan pihak-pihak terkait yang telah berkenan memberikan kesempatan kepada peneliti sehingga proses penelitian dapat berjalan dengan baik dan lancar.

\section{REFERENSI}

Andriani, D. A., Rustiyaningsih, A., \& Haryanti, F. (2017). Factors related to nurse's compassion satisfaction, burnout, and secondary traumatic stress in pediatric care unit RSUP Dr. Sardjito Yogyakarta. Belitung Nursing Journal, 3(5), 577-584.

Austin, C. L., Saylor, R., \& Finley, P. J. (2017). Moral distress in physicians and nurses: Impact on professional quality of life and turnover. Psychological Trauma: Theory, Research, Practice, and Policy, 9(4), 399. 
Beck, C. T. (2011). Secondary traumatic stress in nurses: A systematic review. Archive of psychiatric nursing, 25(1), 1-10.

Craigie, M., Osseiran-Moisson, R., Hemsworth, D., Aoun, S., Francis, K., Brown, J., ... \& Rees, C. (2016). The influence of trait-negative affect and compassion satisfaction on compassion fatigue in Australian nurses. Psychological Trauma: Theory, Research, Practice, and Policy, 8(1), 88.

Crosby, R. H. J. (2000). AMEE Guide No 20: The good teacher is more than a lecturer-the twelve roles of the teacher. Medical teacher, 22(4), 334-347.

Departemen Pendidikan Nasional. (2003). Undang-Undang Nomor 20 Tahun 2003, Tentang Sistem Pendidikan Nasional, Jakarta: Depdiknas.

Departemen Pendidikan Nasional. (2005). Undang-Undang Nomor 14 Tahun 2005, Tentang Guru dan Dosen, Jakarta: Depdiknas.

Duarte, J., Pinto-Gouveia, J., \& Cruz, B. (2016). Relationships between nurses' empathy, selfcompassion and dimensions of professional quality of life: A cross-sectional study. International Journal of Nursing Studies, 60, 1-11.

Eka, N. G. A., Tahulending, P., Kinasih H., \& Yuningsih, I. (2016). Final-year student nurses' professional quality of life. Proceeding on 1st ICGH International Conference on Global Health 2016, Jakarta, Indonesia

Firmansyah, I., \& Widuri, E. L. (2014). Subjective well-being pada guru sekolah luar biasa (SLB). Empathy, 2(1), 1-8.

Hapsari, I. I., \& Mardiana, M. (2016). Empati dan motivasi kerja guru sekolah luar biasa. JPPPJurnal Penelitian dan Pengukuran Psikologi, 5(1), 48-56.

Kelly, L., Runge, J., \& Spencer, C. (2015). Predictors of compassion fatigue and compassion satisfaction in acute care nurses. Journal of Nursing Scholarship, 47(6), 522-528.

Koenig, A. (2014). Learning to prevent burning and fatigue: Teacher burnout and compassion fatigue. Electronic Thesis and Dissertation Repository. https://ir.lib.uwo.ca/etd/1928

Koenig, A., Rodger, S., \& Specht, J. (2017). Educator burnout and compassion fatigue: A pilot study. Canadian Journal of School Psychology, 33(4), 259-278.

Komariyah, S. N., Bagarkorowati, R., \& Lianty, L. (2017). Pemahaman guru terhadap peserta didik berkebutuhan khusus di sekolah dasar inklusif wilayah kepulauan seribu. PARAMETER: Jurnal Pendidikan Universitas Negeri Jakarta, 29(2), 216-222.

Maslach, C., \& Leiter, M. P. (2016). Understanding the burnout experience: Recent research and its implications for psychiatry. World psychiatry, 15(2), 103-111.

Msuya, O. W. (2016). Exploring levels of job satisfaction among teachers in public secondary schools in Tanzania. International Journal of Educational Administration and Policy Studies, 8(2), 9-16.

Pramartha, I. N. B. (2015). Sejarah dan sistem pendidikan sekolah luar biasa bagian a negeri Denpasar Bali. HISTORIA: Jurnal Program Studi Pendidikan Sejarah, 3(2), 67-74.

Sharp-Donahoo, L. M., Siegrist, B., \& Garrett-Wright, D. (2018). Addressing compassion fatigue and stress of special education teachers and professional staff using mindfulness and prayer. The Journal of School Nursing, 34(6), 442-448.

Stamm, B. H. (2010). The concise ProQOL manual ( $2^{\text {nd }}$ Ed.). Pocatello, ID: ProQOL.org.

Sutjiono, B. (2018). Evaluasi properti psikometri professional quality of life pada guru anak berkebutuhan khusus (Tesis tidak dipulikasikan). Universitas Tarumanagara, Jakarta.

Yu, H., Jiang, A., \& Shen, J. (2016). Prevalence and predictors of compassion fatigue, burnout and compassion satisfaction among oncology nurses: A cross-sectional survey. International Journal of Nursing Studies, 57, 28-38. 